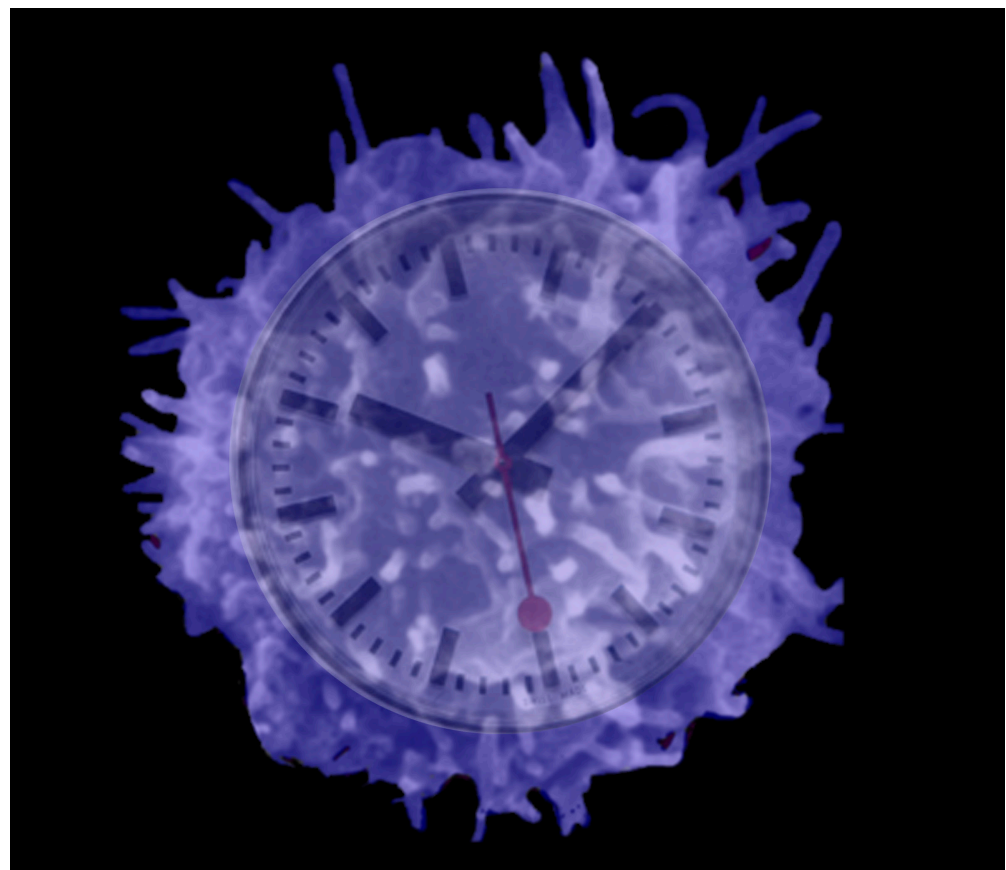

$\mathrm{CD}^{+} \mathrm{T}$ cells accumulate functional defects as they age. ( $\mathrm{T}$ cell image provided by Michael Dustin, New York University, NY, NY.)

\section{Too old to help}

Old mice have reduced $\mathrm{CD}^{+}{ }^{+} \mathrm{T}$ cell function but, according to new data from Haynes and colleagues (page 845), the elderly environment is not to blame. Newly generated $\mathrm{T}$ cells functioned normally in elderly mice, suggesting that strategies to boost $\mathrm{T}$ cell production might be an effective way to improve vaccine efficacy in the elderly.

Previous work by this group has shown that age-related defects in antibody production result from declining $\mathrm{CD}^{+} \mathrm{T}$ cell help, not from faulty B cells. By depleting the existing pool of $\mathrm{CD}^{+} \mathrm{T}$ cells and forcing the thymus to churn out a fresh supply, the authors show that newly generated $\mathrm{CD} 4^{+} \mathrm{T}$ cells are equally responsive to antigen whether they are produced in a young or an old mouse. This suggests that their functional demise depended on the age of the individual $\mathrm{T}$ cell, not on the age of the mouse.

Although there were no detectable phenotypic differences between old and young $\mathrm{T}$ cells, the authors postulate that unknown defects accumulate in $\mathrm{T}$ cells as they divide and age in the periphery. In young mice, the new $\mathrm{T}$ cells produced by the thymus compensate for the reduced function of their elderly predecessors. But thymic output decreases with age, and eventually old $\mathrm{T}$ cells outnumber young ones, causing overall $\mathrm{T}$ cell function to decline. Production of B cells, by contrast, does not decrease as drastically with age, which may explain why B cells are more resistant to the effects of aging.

Although the nature of the defects that accumulate in aging $\mathrm{T}$ cells are not known, recent studies showing an age-related decrease in immune synapse formation between $\mathrm{T}$ cells and antigen presenting cells point to potential alterations in plasma membrane components. Haynes suggests that changes in the lipid composition of the plasma membrane-possibly resulting from routine oxidative stress - may make the membranes less fluid and slow down the movement of key signaling molecules into the immune synapse. JEM

\section{Clean living staves off autoimmunity}

Autoreactive T cells are harmless until they are prodded into action by exposure to common microbes, according to Yoshitomi and colleagues on page 949. These results may help explain the contribution of environmental factors to human autoimmune diseases like rheumatoid arthritis and diabetes.

While studying an arthritis-prone strain of mouse, Yoshitomi et al. noted that these mice did not develop disease when housed in a microbe-free environment, despite the presence of T cells that could induce arthritis when transferred to nude mice. Only when mice were moved to nonsterile conditions (where they acquired fungal infections) or were injected with $\beta$-glucans from fungal cell walls did the telltale symptoms of arthritis appear. Treatment of the mice with antifungal drugs or antibodies that blocked binding of $\beta$-glucans to cells reversed this effect, suggesting a direct link between exposure to fungi and development of disease.

The same fungal products that triggered arthritis stimulated dendritic cells (DCs), the cells responsible for activating $T$ cells, to upregulate costimulatory molecules and secrete cytokines. The authors suspect that $\beta$-glucans, detectable in the circulation during infection, reach the local lymph nodes where they prompt DCs to activate autoreactive T cells. Once activated, the T cells invade the joints. The group now plans to investigate possible defects in regulatory $T$ cells in this model, as these cells normally keep autoreactive T cells in check. JEM

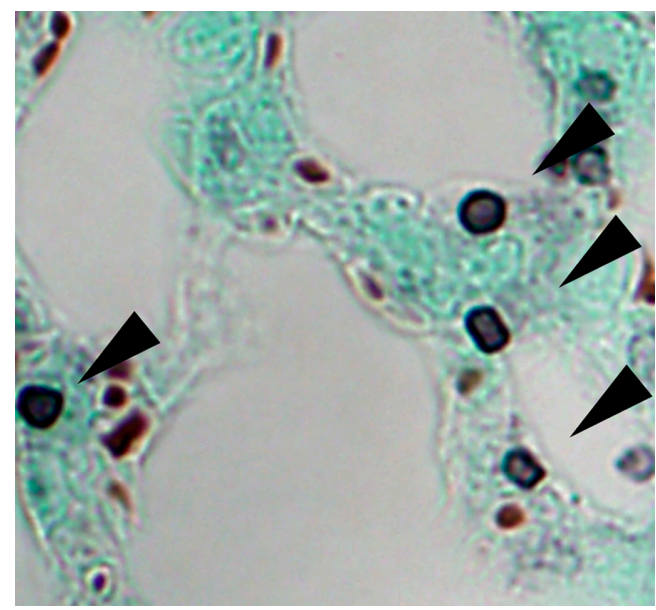

Fungal infections trigger arthritis in susceptible SKG mice (arrowheads indicate fungal spores in the lung). 